\title{
Retraction Note to: New Stabilization Conditions for Takagi- Sugeno Fuzzy Systems Involving Time-Varying Delay and Interval Uncertainties
}

\author{
Xiaoxiao Liu ${ }^{1,2} \cdot$ YuanSheng Wang $^{3}$
}

Published online: 23 September 2021

(C) Taiwan Fuzzy Systems Association 2021

\section{Retraction to: International Journal of Fuzzy Systems (2021) 23(2):434-454 https://doi.org/10. 1007/s40815-020-00938-2}

The authors have retracted this article [1] because after its publication, they noticed that there were faults in the statistical data. These faults have also caused errors in figures 2-5 and tables 1-4. All authors agree to this retraction.

\section{References}

[1] Liu X, Wang Y.: New stabilization conditions for Takagi-Sugeno fuzzy systems involving time-varying delay and interval uncertainties. Int. J. Fuzzy Syst. 23, 434-454 (2021). https://doi.org/10. 1007/s40815-020-00938-2
The original article can be found online at https://doi.org/10.1007/ s40815-020-00938-2.

Xiaoxiao Liu

xxliu1989@mail.xjtu.edu.cn

1 State Key Laboratory for Strength and Vibration of Mechanical Structures, School of Aerospace, Xi'an Jiaotong University, Xi'an 710049, People's Republic of China

2 Aerospace Research Institute, Faculty of Science and Engineering, University of Manchester, Manchester M1 3NJ, UK

3 Department of Mechanical and Civil, Northwestern Polytechnical University, Xi' an 710129, People's Republic of China 